\title{
Radiant exposure effects on physical properties of methacrylate - and silorane-composites
}

\author{
Anderson Catelan ${ }^{1}$, Yoshio Kawano ${ }^{2}$, Paulo Henrique dos Santos ${ }^{3}$, Gláucia Maria Bovi Ambrosano ${ }^{4}$, \\ Ana Karina Bedran-Russo ${ }^{5}$, Flávio Henrique Baggio Aguiar ${ }^{1}$
}

\author{
${ }^{1}$ Universidade Estadual de Campinas - UNICAMP, Piracicaba Dental School, Department of Restorative Dentistry, Piracicaba, SP, Brazil \\ ${ }^{2}$ Universidade de São Paulo - USP, Institute of Chemistry, Department of Fundamental Chemistry, São Paulo, SP, Brazil \\ 3Universidade Estadual Paulista - UNESP, Araçatuba Dental School, Department of Dental Materials and Prosthodontics, Araçatuba, SP, Brazil \\ ${ }^{4}$ Universidade Estadual de Campinas - UNICAMP, Piracicaba Dental School, Department of Social Dentistry, Area of Statistics, Piracicaba, SP, Brazil \\ ${ }^{5}$ University of Illinois at Chicago, College of Dentistry, Department of Restorative Dentistry, Chicago, IL, USA
}

Received for publication: May 25, 2014 Accepted: August 08, 2014

Correspondence to: Anderson Catelan

Department of Restorative Dentistry, Piracicaba Dental School, UNICAMP Av. Limeira, 901, Areião, Caixa Postal 52, CEP 13414-903, Piracicaba, SP, Brasil Phone: +55 19 2106-5337 E-mail: catelan@estadao.com.br

\section{Abstract}

Aim: To evaluate the effect of different radiant exposures on the degree of conversion (DC), Knoop hardness number (KHN), plasticization (P), water sorption (WS), and solubility (S) of different monomer resin-based composites. Methods: Circular specimens $(5 \times 2 \mathrm{~mm})$ were manufactured from methacrylate and silorane composite resins, and light-cured at 19.8, 27.8, 39.6 , and $55.6 \mathrm{~J} / \mathrm{cm}^{2}$, using second-generation LED at $1,390 \mathrm{~mW} / \mathrm{cm}^{2}$. After $24 \mathrm{~h}, \mathrm{DC}$ was obtained using a FT-Raman spectrometer equipped with a Nd:YAG laser, KHN was measured with 50-g load for $15 \mathrm{~s}$, and $\mathrm{P}$ was evaluated on the top and bottom surfaces by the percentage of hardness reduction after $24 \mathrm{~h}$ immersed in absolute alcohol. WS and S were determined according to ISO 4049. Data were subjected to statistical analysis $(\alpha=0.05)$. Results: Methacrylate material presented higher $D C, K H N, P$, and WS than silorane $(p<0.05)$. There was no difference in the $S$ values $(p>0.05)$. The increased radiant exposures improved only the KHN $(p<0.05)$. In general, top surfaces showed higher DC and KHN than bottom, for both materials $(p<0.05)$. The increase of the radiant exposure did not improve most physical properties of the composites and were monomerbase dependent. Conclusions: Chemical composition of the composite resins resulted in different physical properties behavior and could affect the clinical longevity of dental restorations, but overall these properties were not influenced by the different radiant exposures evaluated in the study.

Keywords: composite resins; polymerization; physical properties.

\section{Introduction}

Since the development of the dental composite resin in the 1960s, numerous improvements in its composition and characteristics were made and with the increased demand by patients for esthetic restorations and simplification of the bonding procedures, light-cured composites have been widely used in the dental practice ${ }^{1}$. Currently dental composites are classified in nanofilled, microfilled, or micro/nano hybrid composite resins ${ }^{2}$. These materials are composed basically by polymeric matrix based on methacrylate monomers, inorganic filler particles, silane and photo-initiator system ${ }^{3}$. Bis-GMA (bisphenol-A glycidyl dimethacrylate) is 
the most used monomer in dental composites, however due to its high molecular weight, high viscosity and low mobility, other monomers with lower viscosity and/or higher mobility, as TEGDMA (triethylene glycol dimethacrylate) and UDMA (urethane dimethacrylate), are used to increase the degree of conversion (DC) and crosslinking of the resulting polymer ${ }^{3,4}$.

Methacrylate restorative materials exhibit volumetric polymerization shrinkage ${ }^{5}$, ranging from 1.9 to $3.5 \mathrm{vol} \%{ }^{6}$, and a significant proportion of unreacted monomer due to incomplete $\mathrm{C}=\mathrm{C}$ bond conversion ${ }^{7}$. However, a higher $\mathrm{DC}$ increases the shrinkage strain and the resulting polymerization stress may result in cuspal deflection ${ }^{8}$, de-bonding at adhesive interface, post-operative sensitivity ${ }^{9,10}$, microleakage ${ }^{9}$, marginal staining, secondary caries formation, restoration and dental fractures ${ }^{10}$, affecting the restoration durability. In the attempt to reduce these problems some techniques were proposed to decrease the shrinkage stress effects, such as different incremental composite placement ${ }^{10}$, light-curing protocols and intermediate layer with hybrid glass ionomer or flowable composite ${ }^{11}$.

A low shrinkage monomer was developed from the reaction of the oxirane and siloxane molecules, termed silorane ${ }^{8}$. Silorane network is generated by cationic ringopening polymerization mechanism instead of free radical curing of methacrylate monomers ${ }^{8}$, and more light-curing time to form cations is required to initiate the polymerization reaction $^{5}$. It exhibits lower polymerization shrinkage ${ }^{6,8}$, less than 1 vol\% $\%^{6}$, and mechanical properties comparable to conventional Bis-GMA composites ${ }^{6,11}$.

One factor that cannot be controlled by the dentist during the restorative procedure in deep cavities is the reduction of the light intensity reach into the material due to the distance between guide tip and resinous material surface. Thus, restoration weakening may occur by lower DC and/or formation of more linear polymers, presenting inferior physical properties, such as reduced hardness, increased wear, solubility, and discoloration ${ }^{12}$. The increase of the curing time, and consequently the radiant exposure available for the monomer conversion can improve the physical properties of resin-based materials ${ }^{13,14}$, and thus increase the long-term durability of adhesive restorations ${ }^{2}$.

The DC is an important physical property that may have some impact on the restoration longevity, but this property alone is not enough to characterize the 3-dimensional dental composite structure, as different $\mathrm{C}=\mathrm{C}$ bond concentrations coexist in the same polymer ${ }^{15}$. The same DC value may result in different linear polymer content, which is more susceptible to softening than a more cross-linked polymer ${ }^{16}$. Thus, the study of other physical properties together with DC measurement are better for assessing the performance of dental materials. The objectives of this study were to evaluate the effect of the radiant exposure on the DC, Knoop hardness number (KHN), plasticization (P), water sorption (WS) and solubility (S) of methacrylate- and silorane-based composite resins. The research hypotheses tested were that: (1) there is no difference between the materials and (2) the highest radiant exposure improves the tested physical properties.

\section{Material and methods}

Table 1 presents the materials' composition. Circular specimens ( $5 \mathrm{~mm}$ diameter and $2 \mathrm{~mm}$ thick) were made for KHN and P $(n=10)$, and for DC, WS, and $S(n=5)$. A circular polytetrafluoroethylene (Teflon) mold (Figure 1A) was filled with the composite resin held between two glass slabs separated by Mylar strips and pressed with a 500-g load, to prevent bubble formation and to remove excess material. Cavities were filled with only one increment of composite, which was randomly light-cured set at 0 or $4 \mathrm{~mm}$ from the top surface of the mold using a second-generation lightemitting diode (LED) Bluephase 16i (Vivadent, Bürs, Austria) device at $1,390 \mathrm{~mW} / \mathrm{cm}^{2}$ of irradiance according to Table 2 . A holder coupled to the light source was used to standardize the distance between the light guide tip and material (Figure $1 \mathrm{~B}$ and 1C), controlled by digital caliper (Mitutoyo Sul Americana, Suzano, SP, Brazil) (Figure 1D).

The optical power $(\mathrm{mW})$ delivered by the device was measured with a power meter (Ophir Optronics, Har Hotzvim, Jerusalem, Israel). The tip diameter was measured with a digital caliper (Mitutoyo Sul Americana, Suzano, SP, Brazil) to determine tip area $\left(\mathrm{cm}^{2}\right)$. Irradiance $\left(\mathrm{mW} / \mathrm{cm}^{2}\right)$ was calculated dividing optical power by tip area; and radiant exposure $(\mathrm{J} /$ $\mathrm{cm}^{2}$ ) is the irradiance multiplied by curing time and divided by 1000 . Simulating clinical restorative procedure in a cavity $6 \mathrm{~mm}$ deep, on top surface of first composite increment resulted in 19.8 and $39.6 \mathrm{~J} / \mathrm{cm}^{2}$ radiant exposure, when light polymerized for 20 and $40 \mathrm{~s}$ respectively, at $990 \mathrm{~mW} / \mathrm{cm}^{2}$.

Table 1. Tested materials

\begin{tabular}{cc}
\hline Material & Composition* \\
$\begin{array}{c}\text { Methacrylate (Filtek Z250, A2 shade; 3M } \\
\text { ESPE, St. Paul, MN, USA) }\end{array}$ & Lot. N144001BR \\
& Filler: 60 vol\%, aluminum oxide, silica, and zirconium oxide $(0.01-3.5 \mu \mathrm{m})$. \\
Resin: Bis-GMA, Bis-EMA (ethoxylated bisphenol A dimethacrylate), and UDMA.
\end{tabular}

Silorane (Filtek LS, A2 shade; 3M ESPE, St. Paul, MN, USA)
Lot. N183458

Filler: 55 vol\%, silica, and yttrium trifluoride $(0.04-1.7 \mu \mathrm{m})$

Resin: Bis-3,4-Epoxycyclohexylethyl-Phenyl-Methylsilane and 3,4-

Epoxycyclohexylcyclopolymethylsiloxane. 
Table 2. Experimental groups.

\begin{tabular}{lcc}
\hline Group and material & $\begin{array}{c}\text { Curing time, light-curing } \\
\text { distance and irradiance }\end{array}$ & Radiant exposure \\
G1 Methacrylate / G5 Silorane & $20 \mathrm{~s}, 4 \mathrm{~mm}, 990 \mathrm{~mW} / \mathrm{cm}^{2}$ & $19.8 \mathrm{~J} / \mathrm{cm}^{2}$ \\
G2 Methacrylate / G6 Silorane & $20 \mathrm{~s}, 0 \mathrm{~mm}, 1,390 \mathrm{~mW} / \mathrm{cm}^{2}$ & $27.8 \mathrm{~J} / \mathrm{cm}^{2}$ \\
G3 Methacrylate / G7 Silorane & $40 \mathrm{~s}, 4 \mathrm{~mm}, 990 \mathrm{~mW} / \mathrm{cm}^{2}$ & $39.6 \mathrm{~J} / \mathrm{cm}^{2}$ \\
G4 Methacrylate / G8 Silorane & $40 \mathrm{~s}, 0 \mathrm{~mm}, 1,390 \mathrm{~mW} / \mathrm{cm}^{2}$ & $55.6 \mathrm{~J} / \mathrm{cm}^{2}$ \\
\hline
\end{tabular}

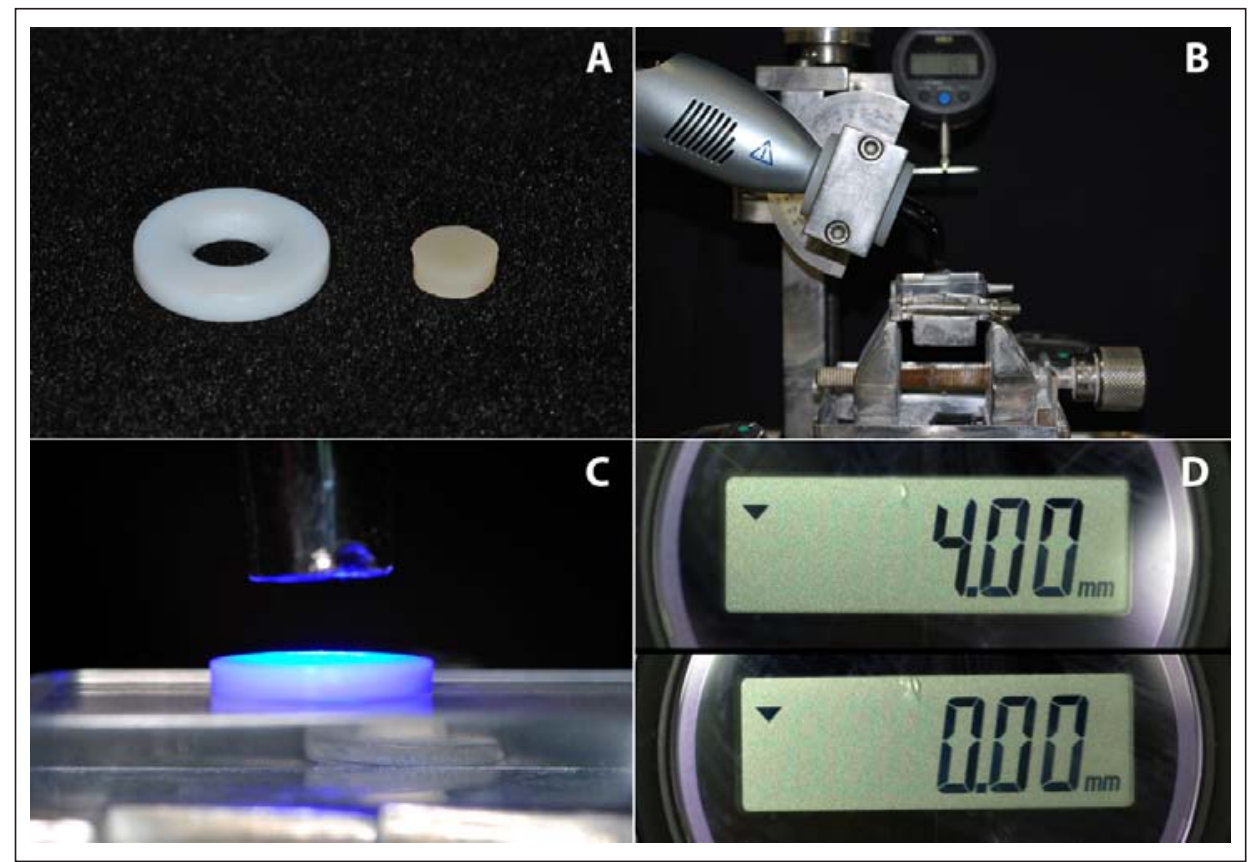

Fig. 1. (A) Teflon ring mold and specimen (5 $\mathrm{mm}$ and $2 \mathrm{~mm}$ thick), (B) holder used to standardize the distance between the light guide tip and material, (C) composite polymerization (D) at 0 and $4 \mathrm{~mm}$ distance controlled by a digital caliper.

The irradiance was calculated at $4 \mathrm{~mm}$ of distance between tip of curing light device and top surface of first composite increment, due its had $2 \mathrm{~mm}$ of thickness. Control groups were light-cured for 20 and $40 \mathrm{~s}$ set at $0 \mathrm{~mm}$ from restorative material surface at $1,390 \mathrm{~mW} / \mathrm{cm}^{2}$, resulting in 27.8 and 55.6 $\mathrm{J} / \mathrm{cm}^{2}$, respectively (Table 2 ).

After polymerization, the specimens were removed from the molds, dry stored in lightproof containers at $37{ }^{\circ} \mathrm{C}$ for 24 h, and polished with 1200-grit silicon carbide (SiC) grinding paper (CarbiMet 2 Abrasive Discs; Buehler, Lake Bluff, IL, USA). The degree of $\mathrm{C}=\mathrm{C}$ conversion assessment was recorded in scattering mode using a Fourier Transform Raman (FT-Raman) spectrometer (RFS 100/S; Bruker Optics Inc., Billerica, MA, USA), equipped with a Nd:YAG laser. Absorption spectra of the cured and uncured composites were obtained on the top and bottom surfaces with 64 scans at 4 $\mathrm{cm}^{-1}$ resolution in the region between 1000-2000 and 600$2000 \mathrm{~cm}^{-1}$ for methacrylate-and silorane-based and siloranebased resins, respectively (Figures 2A-2D). To calculate the $\mathrm{DC}$, the ratios $(\mathrm{R})$ between the peak heights of the $\mathrm{C}=\mathrm{C}$ aliphatic $\left(1638 \mathrm{~cm}^{-1}\right)$ and aromatic $\left(1608 \mathrm{~cm}^{-1}\right)$ for methacrylate, and oxirane $\left(1263 \mathrm{~cm}^{-1}\right)$ and siloxane $(1000$ $\mathrm{cm}^{-1}$ ) for silorane band absorptions for cured and uncured composite were used. According to the formula: DC $(\%)=$ $[1-(\mathrm{R}$ cured/R uncured $)] \times 100$.
Initial microhardness $(\mathrm{MHi})$ reading was measured on the top and bottom surfaces of each specimen using a microhardness tester (HMV-2T; Shimadzu, Tokyo, Japan) with a Knoop diamond indenter under 50-g load for $15 \mathrm{~s}$ (Figures $3 \mathrm{~A}$ and $3 \mathrm{~B}$ ). Five indentations were made on each surface of the specimen, one at the center and other four at a $100 \mu \mathrm{m}$ distance from the central location. The average of the five KHN values was calculated for each specimen.

Plasticization analysis was evaluated by percentage of the microhardness reduction (\%MHred) after absolute alcohol storage $^{16}$. After MHi assessments, all specimens were immersed in $100 \%$ ethanol for $24 \mathrm{~h}$. Following this period, a second microhardness measurement (MHf) was made as previously described. The same operator did the KHN test, before and after alcohol storage. The results were tabulated, and the $\mathrm{P}$ was calculated using the following equation: \% MHred $=100$ [(MHf X 100)/MHi].

The water sorption and solubility were performed in compliance with ISO 4049:2009 standard specifications, except for the specimen dimensions and curing protocol. The specimens were stored in a desiccator at $37{ }^{\circ} \mathrm{C}$ (Figure 3C) containing silica gel and weighted daily on an analical scale (Tel Marke; Bel Quimis, São Paulo, SP, Brazil) accurate to $0.001 \mathrm{mg}$ (Figure 3D), constituting a weighing cycle every $24 \mathrm{~h}$. The complete cycle was repeated to obtain a constant 


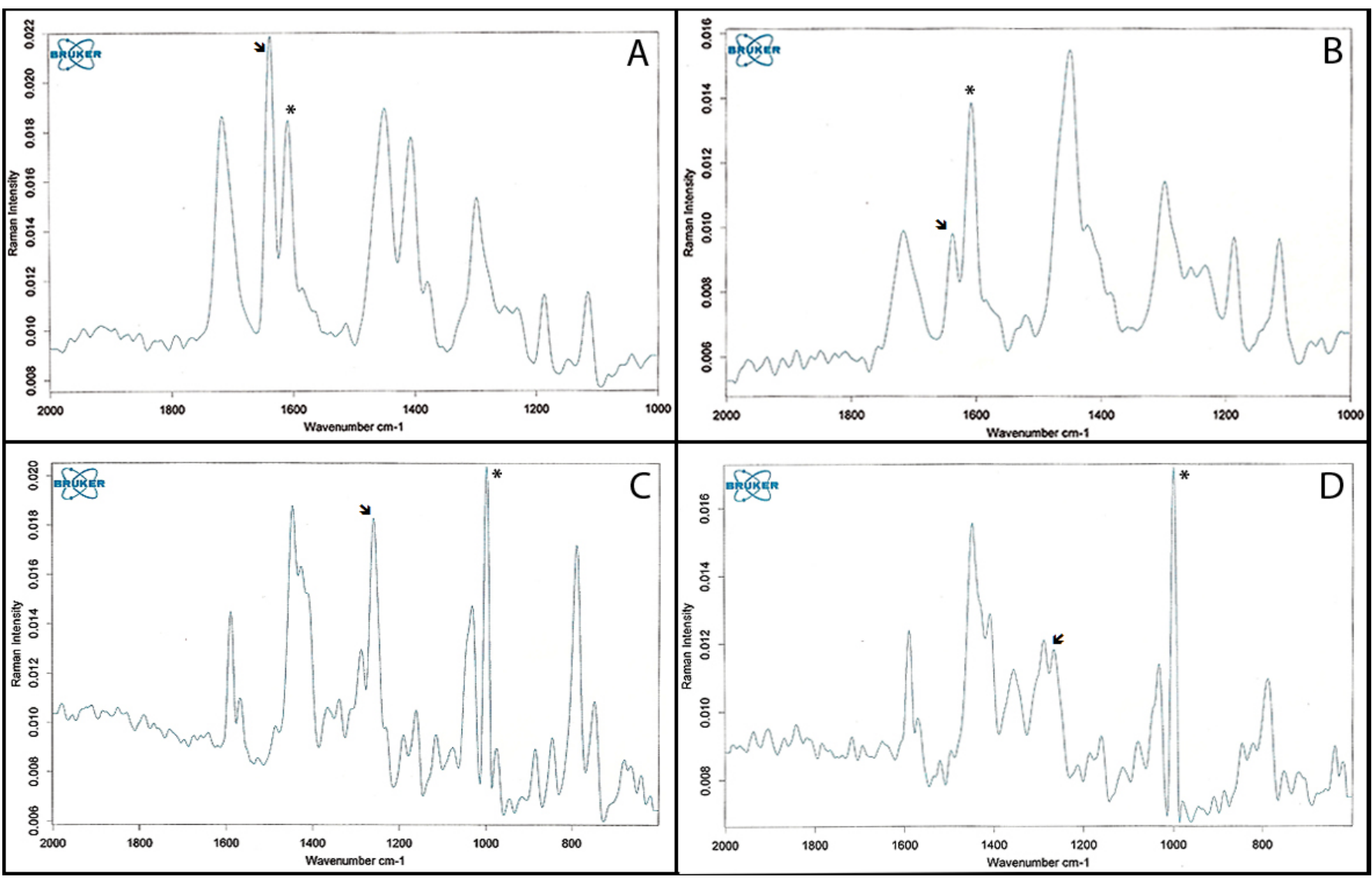

Fig. 2. Absorption spectrum of methacrylate (A-B) and silorane-based composite resin (C-D) uncured and cured, respectively. Asterisk represents the reference peak and arrow the reaction peak.
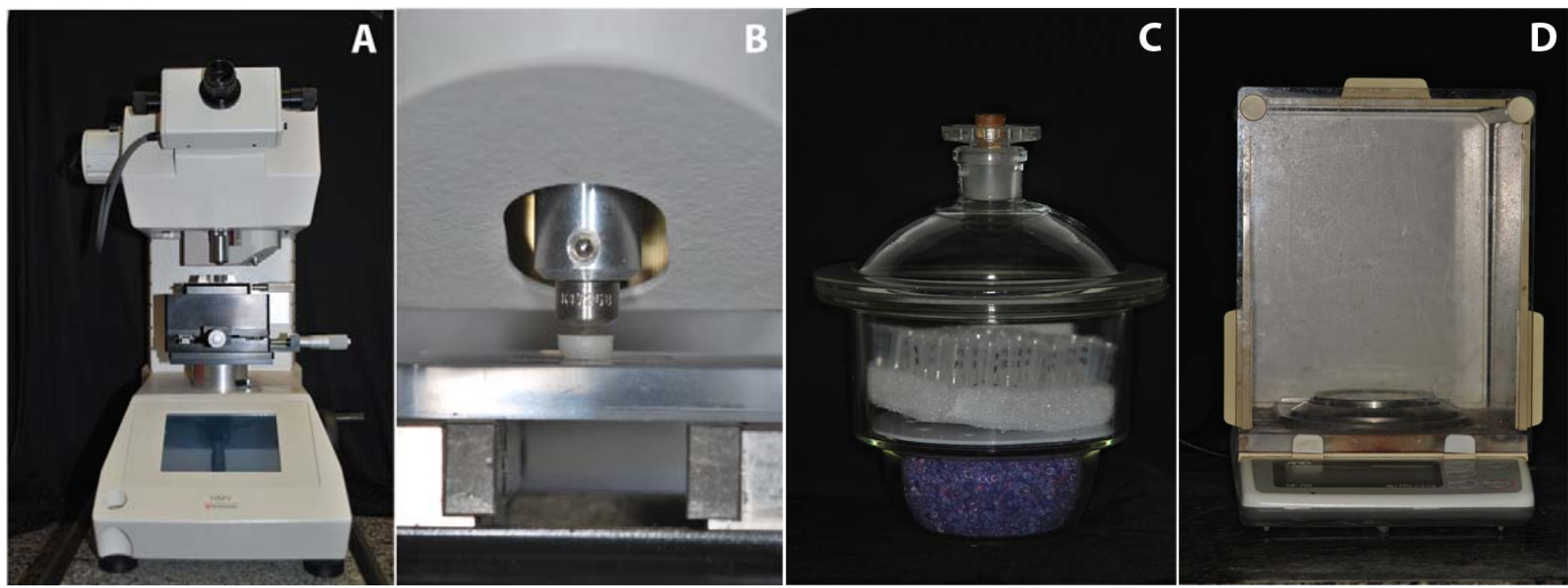

Fig. 3. Hardness tester used for KHN measures (A-B). Desiccator (C) and analytical balance (D) used in the water sorption and solubility tests.

mass (m1): until the mass loss of each specimen was no more than $0.1 \mathrm{mg}$ per $24 \mathrm{~h}$ cycle. Thickness (4 measurements at four equally located points on the circumference) and diameter (2 measurements at right angles) of each specimen were made using a digital electronic caliper. Mean values were used to calculate the volume (v) of each specimen (in $\left.\mathrm{mm}^{3}\right)$.

Thereafter, the specimens were stored in water at $37^{\circ} \mathrm{C}$ for 7 days, the volume for immersion being at least $6 \mathrm{~mL}$ per specimen. Specimens were weighed again after being carefully wiped with an absorbent paper; this value was recorded as $\mathrm{m} 2$. After this weighting, the specimens were returned to the first desiccators, the mass reconditioning cycle was completely repeated and the constant mass was recorded as $\mathrm{m} 3$. The values for $\mathrm{WS}$ and $\mathrm{S}$, in micrograms per cubic millimeters, were calculated using the following equations: $\mathrm{WS}=(\mathrm{m} 2-\mathrm{m} 3) / \mathrm{v}$ and $\mathrm{S}=(\mathrm{m} 1-\mathrm{m} 3) / \mathrm{v}$.

This study had a two-factor experimental design: 
material in 2 levels: methacrylate- and silorane-based microhybrid composite resins and radiant exposure in 4 levels: $19.8,27.8,39.6$ and $55.6 \mathrm{~J} / \mathrm{cm}^{2}$. For DC, KHN and P one subfactor in 2 levels was added: top and bottom surfaces. DC, $\mathrm{KHN}$, and P data were subjected to 2-way split-plot ANOVA and Tukey's test at a pre-set level of 0.05 . The factors material and radiant exposure were considered in the parcels and the sub-factor surface (top and bottom) was considered in the sub-parcel. WS was analyzed by two-way ANOVA and Tukey test $(\alpha=0.05)$. S data did not present homoscedasticity and were submitted to non-parametric Kruskal Wallis, Dunn, and Mann Whitney tests at 5\% significance level.

\section{Results}

Table 3 illustrates the DC of the composite resins. The methacrylate material presented higher curing degree than silorane $(\mathrm{p}<0.001)$, the DC of the top surface also was higher than bottom $(p=0.015)$, and no difference was observed for radiant exposure $(\mathrm{p}>0.05)$.

Silorane material showed lower KHN than methacrylate $(p<0.001)$ as well as bottom compared to top surface $(\mathrm{p}<0.001)$. The factor radiant exposure $(\mathrm{p}<0.001)$ and the interaction of the factor (composite resin) and sub-factor (test surface) showed statistical differences $(p<0.001)$. In general, the highest radiant exposure presented higher KHN, except for the top surface of the silorane composite, which showed no difference among the tested radiant exposures (Table 3).

The P test exhibited lower softening after ethanol storage for silorane than methacrylate resin-based composite $(p<0.001)$. No difference for radiant exposure $(p=0.0586)$ and test surface $(p=0.5504)$ was found (Table 3$)$. In Table 4 , silorane also presented lower water sorption than methacrylate $(p<0.001)$, but no statistical difference for radiant exposure $(p=0.8368)$. There is no difference between the materials and radiant exposures for $\mathrm{S}(\mathrm{p}>0.05)$ (Table 4).

\section{Discussion}

Composite resins are widely used as restorative materials in the dental practice and several clinical studies have reported an adequate durability of resin-based restorations even after an extended period of time ${ }^{2,17}$. The first hypothesis that both materials showed similar performance was partially rejected. Methacrylate composite presented higher DC, KHN, P, and WS than silorane (Tables 3 and 4); only in the $\mathrm{S}$ test no difference was found between the materials (Table 4). According to results of this

Table 3. Degree of conversion (\%), Knoop microhardness number $\left(\mathrm{Kg} / \mathrm{mm}^{2}\right)$, and plasticization $(\%)$ means (standard deviation) of the composite resins according to material, radiant exposure $\left(\mathrm{J} / \mathrm{cm}^{2}\right)$ and test surface.

\begin{tabular}{|c|c|c|c|c|c|c|c|}
\hline \multirow[t]{2}{*}{ Material } & \multirow{2}{*}{$\begin{array}{l}\text { Radiant } \\
\text { exposure }\end{array}$} & \multicolumn{2}{|c|}{ Degree of conversion ${ }^{\dagger}$} & \multicolumn{2}{|c|}{ Microhardness ${ }^{\ddagger}$} & \multicolumn{2}{|c|}{ Plasticization $^{\S}$} \\
\hline & & Top* & Bottom & Top & Bottom & Top & Bottom \\
\hline \multirow[t]{4}{*}{ Methacrylate** } & 19.8 & $62.68(1.67)$ & $61.09(0.72)$ & 63.23 (1.91) Ab & $60.83(1.73) \mathrm{Bb}$ & $47.52(1.90)$ & $45.93(2.08)$ \\
\hline & 27.8 & $63.23(1.39)$ & $63.27(1.95)$ & 64.41 (1.17) Aab & 62.85 (1.09) Aab & $47.27(1.09)$ & $46.19(1.65)$ \\
\hline & 39.6 & $63.90(2.73)$ & $62.25(2.45)$ & 66.17 (3.58) Aa & $64.86(1.55) \mathrm{Aa}$ & $45.93(2.57)$ & $44.06(1.72)$ \\
\hline & 55.6 & $63.93(1.83)$ & $62.97(2.29)$ & $66.65(0.95) \mathrm{Aa}$ & $64.35(1.80) \mathrm{Ba}$ & $46.31(1.36)$ & $44.94(1.57)$ \\
\hline \multirow[t]{4}{*}{ Silorane } & 19.8 & $45.61(2.91)$ & $44.82(2.09)$ & 52.77 (0.90) Aa & $46,42(0.89) \mathrm{Bb}$ & $15.32(3.52)$ & $17.09(3.27)$ \\
\hline & 27.8 & $45.63(1.78)$ & $44.60(0.78)$ & 53.18 (1.53) Aa & 48.75 (1.41) Ba & $14.93(3.25)$ & $16.43(4.42)$ \\
\hline & 39.6 & $45.42(2.36)$ & $44.85(2.08)$ & $53.56(0.96) \mathrm{Aa}$ & 47.78 (1.15) Bab & $13.91(2.53)$ & $16.76(2.73)$ \\
\hline & 55.6 & $46.43(3.30)$ & $45.04(1.92)$ & $52.72(1.48) \mathrm{Aa}$ & $49.23(0.98) \mathrm{Ba}$ & $13.43(2.66)$ & $14.98(3.67)$ \\
\hline
\end{tabular}

TThere was no statistical difference for radiant exposure $(\mathrm{p}>0.05)$. ${ }^{*} \mid \mathrm{t}$ differs from the bottom surface $(\mathrm{p}<0.001)$. ${ }^{*} \mid \mathrm{t}$ differs from the silorane $(\mathrm{p}=0.015)$ "Distinct letters (uppercase letters in the rows and lowercase letters in the columns within each composite) are statistically different (pd"0.05). **lt differs from the silorane $(p<0.001)$.

${ }^{\S}$ There was no statistically significant difference for radiant exposure $(p=0.0586)$ and test surface $(p=0.5504)$. ${ }^{*} \mid$ tt differs from the silorane $(p<0.001)$.

Table 4. Water sorption $\left(\mu \mathrm{g} / \mathrm{mm}^{3}\right)$ and solubility $\left(\mu \mathrm{g} / \mathrm{mm}^{3}\right)$ values of the composite resins according to material and radiant exposure $\left(\mathrm{J} / \mathrm{cm}^{2}\right)$.

\begin{tabular}{|c|c|c|c|c|}
\hline \multirow{2}{*}{$\begin{array}{l}\text { Radiant } \\
\text { exposure }\end{array}$} & \multicolumn{2}{|c|}{ Sorption $^{\dagger}$} & \multicolumn{2}{|c|}{ Solubility $^{\ddagger}$} \\
\hline & Methacrylate* & Silorane & Methacrylate & Silorane \\
\hline 19.8 & $16.41(2.47)$ & $8.97(2.48)$ & $0.00(-4.92 ; 0.00)$ & $0.00(-4.55 ; 0.00)$ \\
\hline 27.8 & $16.61(2.89)$ & $8.48(2.16)$ & $0.00(-4.58 ; 0.00)$ & $0.00(-4.29 ; 0.00)$ \\
\hline 39.6 & $15.53(2.26)$ & $8.44(2.25)$ & $0.00(-4.70 ; 0.00)$ & $0.00(0.00 ; 0.00)$ \\
\hline 55.6 & $15.46(2.18)$ & $8.33(2.09)$ & $0.00(0.00 ; 0.00)$ & $0.00(0.00 ; 0.00)$ \\
\hline
\end{tabular}

${ }^{\dagger}$ Means (standard deviation). *lt differs from the silorane $(p<0.001)$. There was no statistical difference for radiant exposure ( $p>0.8368)$.

${ }^{\ddagger}$ Median (minimum value; maximum value). There was no statistically significant difference among the radiant exposures ( $p=0.4565$ and $p=0.2544$ for methacrylate-and silorane, respectively) and between the composite resins $\left(p=0.9089, p=0.4604, p=0.2126\right.$, and $p=1$ for $19.8,27.8,39.6$, and $55.6 \mathrm{~J} / \mathrm{cm}^{2}$, respectively). 
investigation, higher $\mathrm{DC}^{15,18}$ and $\mathrm{KHN}^{15}$ were found for methacrylate compared to silorane composite. The UDMA monomer contained in the Filtek Z250 composite provides more mobility and has been related to the increase of $\mathrm{DC}^{3}$; and differences in the mechanism of the polymerization reaction can explain these results. Methacrylate is cured by radical intermediates and cycloaliphatic oxirane polymerizes via cationic intermediates ${ }^{6}$. Moreover, the onset of cationic ring-opening polymerization of the silorane is slower due to the required formation of sufficient cations to initiate the polymerization, thus a longer light-curing time is required compared with radical cure of methacrylate monomer molecules into polymer network ${ }^{5}$.

Improvements of the mechanical properties have been associated with the increase of monomer conversion into polymer $^{13,14}$ and also related to the filler fraction of composite resins ${ }^{4}$. The increase of the filler content has been associated with lower volumetric shrinkage due to the reduced volume of organic matrix, but it can affect negatively the DC by mobility restrictions imposed on the reactive species and light scattering ${ }^{19}$. Low hardness usually results in poor wear resistance and has been related to the filler fraction ${ }^{4,20}$. Silorane exhibits 55 vol\% and methacrylate 60 vol\% of inorganic filler. A positive relation between the volume fraction of filler and hardness was found ${ }^{4}$. Thus, the higher DC and filler content of methacrylate could have influenced the higher KHN values than silorane.

Aqueous environment may cause softening of the resinbased materials by swelling of the polymer network and reduction of the frictional forces between polymer chains, resulting in lower hardness ${ }^{15}$. Moreover, the insufficiently cross-linked polymer is more susceptible to plasticization effect by the chemical substances that get in contact during eating and drinking ${ }^{21}$. Silorane is a merger of siloxane and oxirane. Siloxane presents good biocompatibility even in uncured condition and high hydrophobicity; oxirane has low shrinkage and high reactivity ${ }^{6}$. Unchanged Knoop hardness was reported for silorane after storage in water due to the presence of siloxane moiety, while the methacrylate composites were susceptible to softening ${ }^{15}$, and lower ethanol degradation ${ }^{18}$. Thus, the more hydrophobic nature of silorane ${ }^{22}$ may contribute for lower WS and $\mathrm{P}$ compared with a conventional methacrylate-based resin.

The plasticization test has been used to evaluate indirectly the polymer cross-linked structure ${ }^{16}$. The absorption of ethanol molecules by the polar portion of the matrix causes swelling of the resinous material ${ }^{23}$. However, with the different hydrophobicity of the tested monomers, this property is difficult to be correlated, as a material less susceptible to the deleterious effects and absorption of alcohol and with lower crosslink density could present a smaller hardness decrease after ethanol exposure. The solubility of the composite is strongly influenced by monomer conversion ${ }^{24}$ and the high hydrophobicity of siloxane species may decrease the $\mathrm{S}$ of the silorane ${ }^{15}$. Despite of the greater DC of methacrylate, the higher hydrophobicity of silorane composite could have compensated its lower monomer conversion and resulted in the same $\mathrm{S}$ values.

The light-curing time recommended for a silorane composite resin using a quartz-tungsten-halogen (QTH) unit with irradiance between $500-1,400 \mathrm{~mW} / \mathrm{cm}^{2}$ is $40 \mathrm{~s}$, as well as for LEDs with output between $500-1,000 \mathrm{~mW} / \mathrm{cm}^{2}$. For LEDs with irradiance between $1,000-1,500 \mathrm{~mW} / \mathrm{cm}^{2}$ is indicated an exposure light time of $20 \mathrm{~s}$. A second generation LED was used in this study; this device shows a single peak and high irradiance $\left(1,390 \mathrm{~mW} / \mathrm{cm}^{2}\right)$, indicating $20 \mathrm{~s}$ polymerization. This curing unit emits a narrow spectrum (between 410 and $530 \mathrm{~nm}$, with a peak at $454 \mathrm{~nm}$ ) that includes the maximum energy absorption peak of the camphorquinone at $468 \mathrm{~nm}$, which absorbs a wide spectrum of wavelengths from 360 to $510 \mathrm{~nm}^{25}$, a photo-initiator included in both tested composites.

The light radiant exposure that reaches the material is an important factor that provides better physical properties, a higher distance between the tip of light source and irradiated surface decreases the irradiance and can affect the polymerization effectiveness ${ }^{12,26,27}$. Several studies have reported to improve the physical properties of resin-based materials with the increase of radiant exposure, due to the higher $\mathrm{DC}^{13,14}$. In this investigation, the greater radiant exposures increased only the hardness (Table 3), and the second hypothesis also was partially rejected.

During the restorative procedure it is usual that the distance between the light guide tip and first composite increment surface placed at the bottom of cavity be $4 \mathrm{~mm}$ (cavity depth $6 \mathrm{~mm}$ and composite increment $2 \mathrm{~mm}$ ). In this clinical simulation the achieved irradiance was $990 \mathrm{~mW} /$ $\mathrm{cm}^{2}$ at $4 \mathrm{~mm}$, very near to the limit for light-curing during $20 \mathrm{~s}$. Maybe the high light power was sufficient to form more cross-linked polymers ${ }^{7}$, which in spite of improving the mechanical behavior and polymer resistance to degradation, results in the deceleration of the polymerization reaction and limits the conversion rate ${ }^{26}$. Thus, with the used high power LED, the physical properties were little affected. However, special care should be taken when the polymerization of restorative materials using light-curing units with low irradiance power in deep cavities.

The top surface of composites showed higher DC and KHN than bottom, except for methacrylate at 27.8 and 39.6 $\mathrm{J} / \mathrm{cm}^{2}$ (Table 3). Light curing beneath the restorative material at a $4 \mathrm{~mm}$ distance decreased the irradiance to approximately $380 \mathrm{~mW} / \mathrm{cm}^{2}$ at bottom surface. The increased distance between the light guide tip and material, light scattering by filler particles and the thickness of the composite decreased the light intensity that reached the bottom surface of the restorative material ${ }^{12,19}$, resulting in lower DC and for most hardness values of the bottom compared to the top surface of the material.

A previous retrospective longitudinal study showed good performance of two posterior composite resins over 22 years; yet a lower annual failure rate for the higher filler loaded composite was observed, suggesting that physical properties of the material may have some influence on the restoration longevity ${ }^{2}$. So, the small differences in the physical properties 
could result in identical short-term clinical performance, but not over an extended period.

The clinical performance of dental composite restorations could be influenced by the physical properties. Overall, the different radiant exposures evaluated did not affect the tested physical properties, but these properties were influenced by the chemical composition of the composite resin.

\section{Acknowledgements}

This study was supported by FAPESP (\#2010/05666-9 and \#2010/15076-4).

\section{References}

1. Catelan A, Briso AL, Sundfeld RH, dos Santos PH. Effect of artificial aging on the roughness and microhardness of sealed composites. J Esthet Restor Dent. 2010; 22: 324-30.

2. Da Rosa Rodolpho PA, Donassollo TA, Cenci MS, Loguércio AD, Moraes RR, Bronkhorst EM, et al. 22-year clinical evaluation of the performance of two posterior composites with different filler characteristics. Dent Mater. 2011; 27: 955-63.

3. Filho JD, Poskus LT, Guimarães JG, Barcellos AA, Silva EM. Degree of conversion and plasticization of dimethacrylate-based polymeric matrices: influence of light-curing mode. J Oral Sci. 2008; 50: 315-21.

4. Baek DM, Park JK, Son SA, Ko CC, Garcia-Godoy F, Kim HI, et al. Mechanical properties of composite resins light-cured using blue DPSS laser. Lasers Med Sci. 2013; 28: 597-604.

5. Van Ende A, De Munck J, Mine A, Lambrechts P, Van Meerbeek B. Does a low-shrinking composite induce less stress at the adhesive interface? Dent Mater. 2010; 26: 215-22.

6. Weinmann W, Thalacker C, Guggenberger R. Siloranes in dental composites. Dent Mater. 2005; 21: 68-74.

7. Asmussen E, PeutzfeldtA. Influence of selected components on crosslink density in polymer structures. Eur J Oral Sci. 2001; 109: 282-5.

8. Palin WM, Fleming GJ, Nathwani H, Burke FJ, Randall RC. In vitro cuspal deflection and microleakage of maxillary premolars restored with novel low-shrink dental composites. Dent Mater. 2005; 21: 324-35.

9. Duarte S Jr, Phark JH, Varjão FM, Sadan A. Nanoleakage, ultramorphological characteristics, and microtensile bond strengths of a new low-shrinkage composite to dentin after artificial aging. Dent Mater. 2009; 25: 589-600.

10. Mine A, De Munck J, Van Ende A, Cardoso MV, Kuboki T, Yoshida Y, et al. TEM characterization of a silorane composite bonded to enamel/ dentin. Dent Mater. 2010; 26: 524-32.

11. Leprince J, Palin WM, Mullier T, Devaux J, Vreven J, Leloup G. Investigating filler morphology and mechanical properties of new lowshrinkage resin composite types. J Oral Rehabil. 2010; 37: 364-76.

12. Aguiar FH, Lazzari CR, Lima DA, Ambrosano GM, Lovadino JR. Effect of light curing tip distance and resin shade on microhardness of a hybrid resin composite. Braz Oral Res. 2005; 19: 302-6.

13. Borges BC, Souza-Junior EJ, Catelan A, Ambrosano GM, Paulillo LA, Aguiar $\mathrm{FH}$. Impact of extended radiant exposure time on polymerization depth of fluoride-containing fissure sealer materials. Acta Odontol Latinoam. 2011; 24: 47-51

14. Heo YJ, Lee GH, Park JK, Ro JH, García-Godoy F, Kim HI, et al. Effect of energy density on low-shrinkage composite resins: diode-pumped solid state laser versus quartz-tungsten-halogen light-curing unit. Photomed Laser Surg. 2013; 31: 28-35.
15. Kusgoz A, Ülker M, Yesilyurt C, Yoldas $\mathrm{OH}$, Ozil M, Tanriver M. Silorane-based composite: depth of cure, surface hardness, degree of conversion, and cervical microleakage in Class II cavities. J Esthet Restor Dent. 2011; 23: 324-35.

16. Schneider LF, Moraes RR, Cavalcante LM, Sinhoretti MA, CorrerSobrinho L, Consani S. Cross-link density evaluation through softening tests: effect of ethanol concentration. Dent Mater. 2008; 24: 199-203

17. Opdam NJ, Bronkhorst EM, Loomans BA, Huysmans MC. 12-year survival of composite vs. amalgam restorations. J Dent Res. 2010; 89 1063-7.

18. Boaro LC, Gonçalves F, Guimarães TC, Ferracane JL, Pfeifer CS, Braga RR. Sorption, solubility, shrinkage and mechanical properties of "low-shrinkage" commercial resin composites. Dent Mater. 2013; 29 398-404.

19. Gonçalves F, Kawano Y, Braga RR. Contraction stress related to composite inorganic content. Dent Mater. 2010; 26: 704-9.

20. Say EC, Civelek A, Nobecourt A, Ersoy M, Guleryus C. Wear and microhardness of different resin composite materials. Oper Dent. 2003; 28: 628-34.

21. Ferracane JL. Hygroscopic and hydrolytic effects in dental polymer networks. Dent Mater. 2006; 22: 211-22

22. Giannini M, Di Francescantonio M, Pacheco RR, Cidreira Boaro LC, Braga RR. Characterization of water sorption, solubility, and roughness of silorane- and methacrylate-based composite resins. Oper Dent. 2014; 39 264-72.

23. Gerhardt K, Silva AS, Rego G, Sinhoreti MA, Salgado VE, Schneider LF. Bulk and surface properties related to composite filler size. Braz J Oral Sci. 2013; 12: 323-9

24. da Silva EM, Almeida GS, Poskus LT, Guimarães JG. Relationship between the degree of conversion, solubility and salivary sorption of a hybrid and a nanofill resin composite. JApplied Oral Sci. 2008; 16: 161-6.

25. Faria-e-Silva AL, Lima AF, Moraes RR, Piva E, Martins LR. Degree of conversion of etch-and-rinse and self-etch adhesives light-cured using QTH or LED. Oper Dent. 2010; 35: 649-54.

26. Catelan A, Ambrosano GM, Lima DA, Marchi GM, Aguiar FH. Influence of radiant exposure on degree of conversion, water sorption and solubility of self-etch adhesives. Int J Adhes Adhes. 2013; 46: 40-3.

27. Torres SA, Silva GC, Maria DA, Campos WR, Magalhães CS, Moreira AN. Degree of conversion and hardness of a silorane-based composite resin: effect of light-curing unit and depth. Oper Dent. 2014; 39: E137-46. 